Full Length Article

\title{
Does transcranial direct current stimulation during writing alleviate upper limb freezing in people with Parkinson's disease? A pilot study
}

\author{
Sanne Broeder ${ }^{\mathrm{a}, *}$, Elke Heremans ${ }^{\mathrm{a}}$, Marcelo Pinto Pereira ${ }^{\mathrm{a}, 1}$, Evelien Nackaerts ${ }^{\mathrm{a}}$, \\ Raf Meesen ${ }^{\mathrm{b}, \mathrm{c}}$, Geert Verheyden ${ }^{\mathrm{a}}$, Alice Nieuwboer ${ }^{\mathrm{a}}$

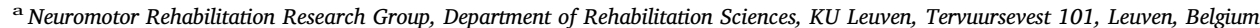 \\ ${ }^{\mathrm{b}}$ Movement Control and Neuroplasticity Research Group, Department of Kinesiology, KU Leuven, Tervuursevest 101, Leuven, Belgium \\ ${ }^{\mathrm{c}}$ Rehabilitation Research Institute, Biomedical Research Institute, Campus Diepenbeek, Hasselt University, Agoralaan Gebouw C, Diepenbeek, Belgium
}

\section{A R T I C L E I N F O}

\section{Keywords:}

Parkinson's disease

Transcranial direct current stimulation

Non-invasive brain stimulation

Upper limb freezing

Handwriting

\begin{abstract}
A B S T R A C T
Transcranial direct current stimulation (tDCS) over the primary motor cortex (M1) can boost motor performance in Parkinson's disease (PD) when it is applied at rest. However, the potential supplementary therapeutic effect of the concurrent application of tDCS during the training of motor tasks is largely unknown. The present study examined the effects of tDCS on upper limb motor blocks during a freezing-provoking writing task (the funnel task) requiring up- and downstroke movements at alternating amplitudes. Ten PD patients and 10 age-matched controls underwent two sessions of writing combined with 20 min of anodal or sham tDCS on the left M1 in a randomized cross-over design. The primary outcome was the number of upper limb freezing episodes during five trials of the funnel task on a touch-sensitive tablet. PD patients showed a significant reduction in freezing episodes during tDCS compared to sham. No effects of tDCS were found for the amplitude, variability and speed of the strokes outside the freezing episodes. However, patients who reported freezing episodes in daily life $(\mathrm{N}=6)$ showed a beneficial effect of tDCS on stroke characteristics. These results indicate a subgroup-dependent variability in response to non-invasive brain stimulation applied during the performance of motor tasks in PD. This warrants future studies to examine tDCS as an adjuvant tool for training programs aimed to reduce motor deficits related to freezing.
\end{abstract}

\section{Introduction}

Freezing in Parkinson's disease (PD) is a sudden and often unpredictable interruption of voluntary movement (Perez-Lloret et al., 2014). It typically occurs during complex and sequential movements and is mostly described during gait. Yet, freezing can also interrupt speech and repetitive upper limb movements such as handwriting (Heremans et al., 2015; Moreau et al., 2007; Vercruysse, Gilat et al., 2014). In general, people with PD demonstrate problems with amplitude maintenance and variability during writing (Broderick, Van Gemmert, Shill, \& Stelmach, 2009; Lange et al., 2006; Ponsen, Daffertshofer, Wolters, Beek, \& Berendse, 2008; Van

\footnotetext{
* Corresponding author at: Department of Rehabilitation Sciences, KU Leuven, Tervuursevest 101, bus 1501, 3001 Leuven, Belgium.

E-mail addresses: sanne.broeder@kuleuven.be (S. Broeder), elke.heremans@kuleuven.be (E. Heremans), evelien.nackaerts@kuleuven.be (E. Nackaerts), raf.meesen@uhasselt.be (R. Meesen), geert.verheyden@kuleuven.be (G. Verheyden), alice.nieuwboer@kuleuven.be (A. Nieuwboer).

${ }^{1}$ Present address: Posture and Locomotion Studies Laboratory, Physical Education Department-UNESP, Sao Paulo State University, Avenue 24-A-1515, Rio Claro,
} Brazil. 
Gemmert, Adler, \& Stelmach, 2003; Van Gemmert, Teulings, Contreras-vidal, \& Stelmach, 1999). These deficits were found to be more pronounced in PD patients with freezing than in those without (Heremans et al., 2016), even with optimal medical management. Pharmacological and surgical interventions only partially restore handwriting deficits (Bidet-Ildei, Pollak, Kandel, Fraix, \& Orliaguet, 2011) and are also often ineffective for freezing of gait in PD (Bidet-Ildei et al., 2011; Giladi, 2008; Nonnekes et al., 2015; Nutt et al., 2011). A recent study demonstrated robust improvements of writing amplitude after intensive writing training even after 6-weeks follow-up (Nackaerts et al., 2016). However, these benefits came at some cost for other parameters of writing (e.g. writing fluency) (Nackaerts, Broeder et al., 2017). As well, the consolidation of the effect was hampered specifically in the subgroup of patients who also experienced gait freezing (Heremans et al., 2016). These results imply a specific need for methods boosting the learning effect particularly in this group. Recent evidence shows that stimulation of specific brain areas with non-invasive brain stimulation (e.g. transcranial magnetic stimulation (TMS) or transcranial direct current stimulation (tDCS)) can be used as a supplementary therapeutic option to enhance training benefits (Benninger \& Hallett, 2015; Buch et al., 2017). Pairing tDCS with a biologically relevant stimulus (i.e. online tDCS-mediated performance) can induce increased behavioral and learning improvements (Buch et al., 2017; Galea \& Celnik, 2009; Kaski, Dominguez, Allum, Islam, \& Bronstein, 2014; Reis \& Fritsch, 2011). However, interindividual variability in tDCS effects as well as optimal stimulation parameters are not completely understood yet (Buch et al., 2017).

Several studies used tDCS as a single or adjuvant intervention in Parkinson rehabilitation (for reviews see Broeder et al., 2015; Elsner, Kugler, Pohl, \& Mehrholz, 2016; Ferrucci, Mameli, Ruggiero, \& Priori, 2016; Goodwill et al., 2017; Tahtis \& Kaski, 2017). Improvements in upper limb performance of PD patients were found after anodal tDCS compared to sham when stimulation was applied to the primary motor cortex (M1) in rest (Benninger et al., 2010; Cosentino et al., 2017; Fregni et al., 2006) as well as during task performance (Salimpour, Mari, \& Shadmehr, 2015). Moreover, changes in M1 excitability after repetitive TMS of the supplementary motor area (SMA) in rest were related to increased writing performance in PD (Randhawa, Farley, \& Boyd, 2013). Studies examining freezing of gait (FOG), showed a reduction in the number and duration of FOG, lasting for 4 weeks, after multiple M1-tDCS sessions in rest (Valentino et al., 2014) as well as improvements after repetitive TMS when applied to M1 or the prefrontal cortex (Chang et al., 2017; Dagan, Herman, Mirelman, Giladi, \& Hausdorff, 2017; Kim et al., 2015; Lee et al., 2014). Not surprisingly, the findings of these studies are not consistent (Rektorova, Sedlackova, Telecka, Hlubocky, \& Rektor, 2007; Tard, Devanne, Defebvre, \& Delval, 2016), as FOG is a very complex symptom (Nutt et al., 2011). So far, no studies have been conducted on the effects of noninvasive brain stimulation on freezing of the upper limbs (FOUL). Not only is targeting FOUL clinically relevant, as it hampers daily life activities, freezing during upper limb movements also offers a model for evaluating the effects of tDCS on sequential motor breakdown, which also underpins FOG. As such, investigating FOUL offers the opportunity to specifically examine underlying mechanisms of freezing episodes in PD. The objective of the current study is to investigate the effects of tDCS on FOUL and writing performance when applied while participants perform a freezing provoking task. Based on previous studies, it is hypothesized that online M1-tDCS-mediated motor performance will show larger improvements compared to sham and this more so in PD than in healthy controls. In addition, this study explored inter-individual variability in tDCS effects by examining whether results were different in patients with and without self-reported freezing in daily life. As such, this study offers a first step towards unravelling the potential value of combining tDCS with training to address sequential upper limb motor deficits in PD.

\section{Methods}

\subsection{Participants}

Twenty right-handed subjects participated in the experiment; 10 PD patients and 10 age-matched healthy controls. Demographics and clinical characteristics of the participants are specified in Table 1. Inclusion criteria for PD patients consisted of: (i) idiopathic PD, diagnosed according to the United Kingdom PD Society Brain Bank criteria (Hughes, Daniel, Kilford, \& Lees, 1992), (ii) Hoehn and Yahr (H\&Y) stage II to III in the 'on'-phase of the medication cycle (Hoehn \& Yahr, 1967) and (iii) most affected on the right side of

Table 1

Subject characteristics.

\begin{tabular}{llll}
\hline & PD $(\mathrm{N}=10)$ & HC $(\mathrm{N}=10)$ & P-value \\
\hline Age (years) & $63.2( \pm 9.2)$ & $64.5( \pm 7.6)$ & 0.74 \\
Gender (M/F) & $8 / 2$ & $5 / 5$ & 0.35 \\
Edinburgh handedness Inventory & $100.0(72.5,100.0)$ & $100.0(66.3,100.0)$ & 0.83 \\
MoCA (0-30) & $27.5(23.8,30.0)$ & $27.5(26.0,29.3)$ & - \\
Disease duration (years) & $6.95( \pm 5.1)$ & - & - \\
MDS-UPDR III (0-132) & $17.5(13.0,22.0)$ & - & - \\
H\&Y (0-5) & $2.0(2.0,2.0)$ & - & - \\
LED (mg/24h) & $407.0( \pm 300.4)$ & - & - \\
NFOG-Q (0-28) & $0.0(0.0,12.8)$ & & - \\
\hline
\end{tabular}

Abbreviations: $\mathrm{HC}=$ healthy control subjects; H\&Y stage $=$ Hoehn and Yahr stage; LED = levodopa equivalent dose; MDS-UPDRS = Movement Disorders Society Unified Parkinson's disease rating scale; MoCA = Montreal Cognitive Assessment; NFOG-Q = New freezing of gait questionnaire; PD = patients with Parkinson's disease.

Results are presented as the mean ( \pm standard deviation) for normally distributed variables and as the median (1st quartile, 3rd quartile) for non-normally distributed variables. 
the body as assessed by lateralized scores of part III of the Movement Disorders Society Unified Parkinson's disease rating scale (MDSUPDRS) (Goetz et al., 2008). The inclusion criteria for both PD patients and control subjects were: (i) right-handedness as measured by means of the Edinburgh handedness Inventory (Oldfield, 1971), Dutch translation laterality quotient $\geq 40$, (ii) Mini-mental State Examination (MMSE) (Folstein, Folstein, \& McHugh, 1975) score $\geq 24$, (iii) the absence of upper limb problems which could interfere with the measurements, (iv) the absence of visuospatial deficits (i.e. Rey-Osterrieth Complex Figure Test (Poreh \& Shye, 1998) score copy trial $\geq 32$ ) and (v) no former anodal tDCS intervention. This study was approved by the local Ethics Committee of the KU Leuven in accordance with The Code of Ethics of the World Medical Association (Declaration of Helsinki, 1967). Informed consent was obtained from all participants prior to participation, after explanation of the study protocol. The study was part of a larger trial registered as ClinicalTrials.gov Protocol Record NCT02287207.

\subsection{Experimental procedure and tasks}

During a baseline session, the overall cognitive status (Montreal Cognitive Assessment (MoCA)) (Nasreddine et al., 2005) and right-handedness (Edinburgh Handedness Inventory) (Oldfield, 1971) of all participants was checked before entering the study. In addition, disease severity, medication intake and the occurrence of freezing episodes of patients in daily life were assessed by respectively the MDS UPDRS part III (Goetz et al., 2008), the Levodopa Equivalent Dose (LED), the New Freezing of Gait Questionnaire (NFOG-Q) (Nieuwboer, Rochester et al., 2009) and the Non-Gait Freezing Questionnaire (NGF-Q) (Vercruysse, Devos et al., 2012). Next, all participants received two sessions of writing combined with tDCS or sham stimulation in a randomized, single blind cross-over design with a 3-week washout period. PD patients were tested in the on-phase of the medication cycle approximately 1-1.5 $\mathrm{h}$ after medication intake.

The tDCS (or sham) concurrently applied with motor performance lasted $20 \mathrm{~min}$. Online motor performance consisted of three bouts (i.e. two runs cued and one run without visual cues) of writing several sequences of letters (lasting each approximately 3 min) followed by execution of the funnel task, which is able to elicit freezing episodes (Fig. 1A) (Heremans et al., 2015). For this study we aimed to examine tDCS effects on FOUL and therefore the focus of this paper is on the analysis of the funnel task. This task includes five trials of alternating up- and down-strokes on a 6.4-inch touch-sensitive writing tablet (sampling frequency $200 \mathrm{~Hz}$; spatial resolution $32.5 \mu \mathrm{m}$ ) (Fig. 1B). Each trial requires adapting the amplitude to constant small $(0.6 \mathrm{~cm})$ and large $(2.0 \mathrm{~cm})$ sizes as well as to gradually increasing (from $0.6 \mathrm{~cm}$ to $2.0 \mathrm{~cm}$ ) and decreasing (from $2.0 \mathrm{~cm}$ to $0.6 \mathrm{~cm}$ ) sizes over a trajectory of $13 \mathrm{~cm}$. The requested writing size was indicated by blue target zones with a bandwidth of $1 \mathrm{~mm}$ per zone (i.e. upper and lower target zone). All participants were instructed to write with an amplitude as indicated (i.e. the distance between the middle of the lower line and the middle of the upper line) at a comfortable speed. The researcher corrected deviating horizontal distances between the strokes when deviations occurred, before and during testing. However, no specific instructions were given about the expected horizontal distance or angle of the strokes. All trials were initiated with a starting tone and were preceded by a break of six seconds together with a 3-s instruction of the upcoming trial. Participants were given a maximum duration of 1 min to complete each trial. Before the start, participants received a demonstration of the task by the researcher and performed one practice trial on paper and one on the writing tablet to make sure that the task was well-understood and that there were no problems with seeing the task on the screen.

\subsection{Transcranial direct current stimulation}

During the concurrent motor tasks, tDCS was delivered with an intensity of $1 \mathrm{~mA}$ via two electrodes with a $5 \mathrm{~cm} \times 7 \mathrm{~cm}$ surface area resulting in a current density of $0.03 \mathrm{~mA} / \mathrm{cm}^{2}$ (DC-Stimulator, NeuroConn GmbH, Germany). A pair of saline-soaked sponges,

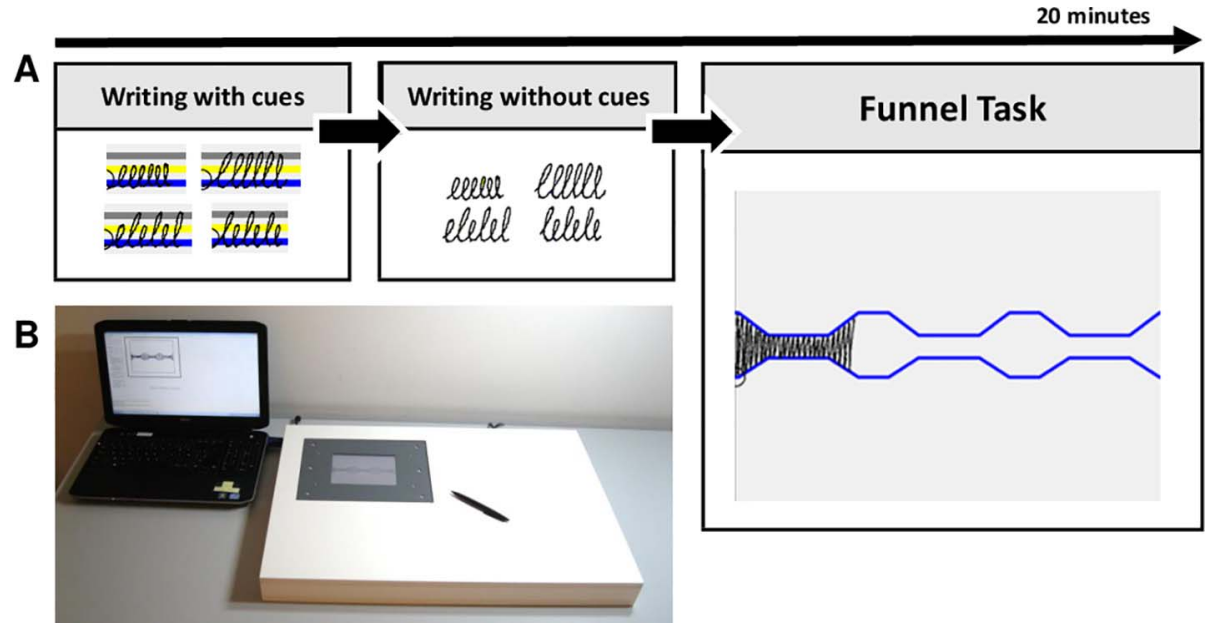

Fig. 1. Experimental material and tasks. (A) Online motor tasks: writing several sequences of letters in a cued and a non-cued condition followed by execution of the freezing-provoking writing task (i.e. Funnel Task). (B) The touch-sensitive writing tablet. 
covered with conductive gel, were used to optimize conductivity. The contact impedance was monitored throughout the sessions to ensure it stayed below $10 \mathrm{k} \Omega$. The mean (standard deviation) impedance for all participants was 5.8 (1.6) $\mathrm{k} \Omega$. The center of the anode was placed over the left primary motor cortex (M1) (i.e. C3 of the 10-20 international system of electrode placement). The cathodal reference electrode was positioned over the right supraorbital area.

During real tDCS, a constant current of $1 \mathrm{~mA}$ was maintained for $20 \mathrm{~min}$, including a $10 \mathrm{~s}$ ramp-up and ramp-down period. For sham stimulation, the current was applied for $30 \mathrm{~s}$, which is a feasible method for blinding participants (Gandiga, Hummel, \& Cohen, 2006). Following each intervention, a visual Analogue (VAS) questionnaire for assessing sensations during stimulation was completed by all participants to check for the success of blinding.

\subsection{Data processing}

In total, for all participants together, 200 trials were analyzed; 100 trials during tDCS and 100 trials during sham. The number and duration (s) of freezing episodes as well as the number of trials with FOUL, were determined in line with previous studies on upper limb freezing (Heremans et al., 2015; Vercruysse, Spildooren et al., 2012). Freezing episodes were defined as an involuntary inability to perform effective alternating up- and down-strokes. After processing in Matlab R2017b (Mathworks), these writing blocks were visually detected and characterized by (i) a decreased amplitude of more than $50 \%$ of the target size, (ii) an irregular cycling frequency of the movement and/or (iii) an increased freezing index (Heremans et al., 2015; Moore, MacDougall, \& Ondo, 2008). To distinguish intentional stops from FOUL, voluntary stops were documented during data collection and episodes with a movement arrest were double-checked via video analyses. Three raters, of which two were independent and blinded for the sham or tDCS exposure, analyzed all trials for the presence of FOUL, with disagreements resolved by an independent fourth rater. Only freezing episodes with a minimum duration of $1 \mathrm{~s}$ were included for further analysis (Heremans et al., 2015).

Subsequently, freezing epochs were removed to analyze amplitude (\% of target size), velocity (cm/s) and the coefficients of variation of the within-subject stroke amplitude $\left(\mathrm{COV}_{\mathrm{ampl}}\right)$ and velocity $\left(\mathrm{COV}_{\mathrm{vel}}\right)$ outside the freezing episodes. Additionally, the horizontal distance between the maxima and minima of the strokes were analyzed. The amplitude of individual up and down strokes was calculated as the distance between local minima and maxima and expressed as a percentage of the target size. The time to complete each stroke was computed in seconds for determining the writing velocity $(\mathrm{cm} / \mathrm{s})$. The ratio of the standard deviation to the absolute mean, represented the $\operatorname{COV}_{\mathrm{ampl}}(\%)$ and $\operatorname{COV}_{\mathrm{vel}}(\%)$. Average horizontal distance between local maxima and minima were calculated in mm. All parameters were estimated separately for each part of the funnel (i.e. small, large, decreasing and increasing size).

\subsection{Statistical analysis}

\subsubsection{Clinical outcomes}

Data were analyzed using SPSS software (version 24 SPSS, Inc., Chicago, IL, USA) with significance levels of $\alpha<0.05$. After checking the normality of distribution and equality of variance, appropriate parametric (i.e. Independent Samples T-Test) or nonparametric (i.e. Mann-Whitney U Test or Chi-square Test) tests were used to compare differences between PD patients and healthy controls.

The non-gait freezing questionnaires (NGF-Q scores) were compared (Mann-Whitney U Test) within the PD group. Based on the NGF-Q, patients were separated in those with $(\mathrm{N}=6)$ and without $(\mathrm{N}=4)$ freezing episodes during repetitive tasks in daily life, such as tooth brushing and screw driving (respectively, PD + FR and PD-FR). PD + FR were defined by a score of 1 or more and PD-FR had a score of 0 on the NGF-Q. To examine the blinding of the participants to the stimulation condition, scores of the VAS for assessing sensations during stimulation were analyzed with a Wilcoxon signed-rank test.

\subsubsection{Upper limb freezing episodes}

Differences in the total number of FOUL episodes during tDCS and sham between PD + FR and PD-FR were compared using Mann-Whitney U Tests. The effects of stimulation condition (i.e. tDCS or sham) on FOUL outcomes between patients with PD and healthy controls were compared using a linear mixed effect model approach with Bonferroni post hoc analysis. Group (PD or healthy controls), Condition (real tDCS or Sham) and Size (small, large, decreasing and increasing) were incorporated as fixed factors.

\subsubsection{Strokes outside the freezing episodes}

Strokes outside the freezing episodes were analyzed using linear mixed effect models with Group (PD or healthy controls), Condition (real tDCS or Sham) and Size (small, large, decreasing and increasing) as fixed factors. An exploratory sensitivity analysis was performed with the PD group separated in PD + FR and PD-FR. The linear mixed effect model included Group (PD + FR or PD-FR), Condition (real tDCS or Sham) and Size (small, large, decreasing and increasing) as fixed factors and LED as a covariate. Because LED values were irrelevant for healthy participants, the control group was not included in this analysis. To examine differences between PD + FR, PD-FR and healthy subjects, a separate linear mixed effect model was conducted with Group (PD + FR, PD-FR or healthy controls), Condition (real tDCS or Sham) and Size (small, large, decreasing and increasing) as fixed factors without covariates.

\subsubsection{Correlations}

Spearman's rank correlations were performed to assess associations between clinical characteristics (i.e. age, gender, cognitive ability as well as disease characteristics for PD patients) and FOUL outcomes (i.e. occurrence and number of FOUL episodes). For this 
Table 2

Freezing outcomes for patients with Parkinson's disease $(\mathrm{N}=10)$.

\begin{tabular}{|c|c|c|c|}
\hline Patient number & NGF-Q (0-9) & FOUL during sham & FOUL during tDCS \\
\hline 1 & 0 & 0 & 2 \\
\hline 2 & 0 & 0 & 0 \\
\hline 3 & 0 & 2 & 1 \\
\hline 4 & 0 & 11 & 6 \\
\hline 5 & 3 & 0 & 0 \\
\hline 6 & 2 & 10 & 1 \\
\hline 7 & 4 & 0 & 1 \\
\hline 8 & 6 & 12 & 0 \\
\hline 9 & 6 & 1 & 0 \\
\hline 10 & 2 & 2 & 1 \\
\hline $\begin{array}{l}\text { PD-FR median } \\
\text { (1st quartile, 3rd quartile) }\end{array}$ & $0.0(0.0,0.0)$ & $1.0(0.0,8.8)$ & $1.5(0.3,5.0)$ \\
\hline $\begin{array}{l}\mathrm{PD}+\mathrm{FR} \text { median } \\
\quad \text { (1st quartile, 3rd quartile) }\end{array}$ & $3.5(2.0,6.0)$ & $1.5(0.0,10.5)$ & $0.5(0.0,1.0)$ \\
\hline P-value between groups & $0.010^{*}$ & 0.762 & 0.257 \\
\hline
\end{tabular}

Abbreviations: FOUL $=$ freezing of the upper limb; NGF-Q = Non-Gait Freezing Questionnaire; tDCS = transcranial direct current stimulation.

* Groups significantly different at $\mathrm{P}<0.05$ (Mann-Whitney $U$ ).

analysis, an additional binary score was calculated for the occurrence of FOUL during tDCS and sham stimulation (yes/no). Similar correlation analyses were conducted for the associations between clinical characteristics and stroke measures (i.e. amplitude and velocity) and FOUL. For all correlation analyses, the average performance of the four parts of the task (i.e. small, large, decreasing and increasing) was used.

\section{Results}

\subsection{Clinical outcomes}

All included participants completed both sessions of the study and no adverse events of tDCS were reported. There was no significant difference between the VAS scores after tDCS and sham stimulation $(\mathrm{z}=1.332, \mathrm{p}=0.183)$. Patients with PD and healthy control subjects were matched for age, gender, right-handedness and cognition (Table 1). When comparing PD + FR and PD-FR, a significant difference was found for the LED $(t(8)=2.444, p=0.040)$. All other clinical outcomes were not significantly different between the two patient groups.

\subsection{Upper limb freezing episodes}

Table 2 provides the scores of the NGF-Q as well as the number of FOUL episodes during tDCS and sham for all PD patients. All patients with FOG also showed actual FOUL episodes during sham. In addition, two healthy control subjects showed three freezing episodes (i.e. two during sham and one during tDCS). Comparing the effects of stimulation condition between patients with PD and healthy controls revealed significant Group $\times$ Condition $(F(1126)=5.764, p=0.018)$ and Group $\times$ Size $(F(3126)=2.764$, $\mathrm{p}=0.045$ ) interactions for the number of FOUL episodes. In addition, a tendency for a significant Size $\times$ Condition interaction was found $(\mathrm{F}(3126)=2.395, \mathrm{p}=0.071)$. Post hoc analysis showed significantly more FOUL episodes in the small $(0.6 \mathrm{~cm}) \mathrm{compared}$ to the large $(2.0 \mathrm{~cm})$ parts of the task for PD patients $(\mathrm{p}<0.0005)$. Compared to healthy controls, PD patients also experienced significantly more FOUL episodes in the small parts of the task $(\mathrm{p}=0.001)$. The complete set of absolute FOUL episodes per part of the task is provided in the appendix Table A.1. Post hoc tests showed that tDCS significantly reduced the number of FOUL episodes for PD patients compared to sham stimulation $(\mathrm{p}=0.001)$ (Fig. 2A). During sham stimulation PD patients also showed more FOUL compared to healthy controls $(\mathrm{p}=0.003)$. No significant interactions were found for the duration of FOUL episodes.

For PD patients, a total of 50 trials per condition (i.e. tDCS or sham) were analyzed. Results showed 38 FOUL episodes in 19 trials when PD patients received sham stimulation (i.e. in 38\% of the trials). During tDCS, 12 episodes in 9 trials were found (i.e. in 18\% of the trials) (Fig. 2B). No differences in the total number of FOUL episodes during tDCS and sham were found between PD + FR and PD-FR (Table 2). Of the six PD + FR, based on self-reported NGF-Q scores, four patients showed FOUL during sham stimulation. In contrast, two patients without self-reported non-gait freezing episodes in daily life (i.e. PD-FR), showed FOUL when sham stimulation was applied (Table 2).

\subsection{Strokes outside the freezing episodes}

\subsubsection{PD patients compared to healthy controls}

In the writing parts outside the freezing episodes a significant Group x Size interaction was found for the amplitude when comparing PD patients and healthy controls $(\mathrm{F}(3126)=5.05, \mathrm{p}=0.003)$. Post hoc analysis showed that PD patients wrote with 
A

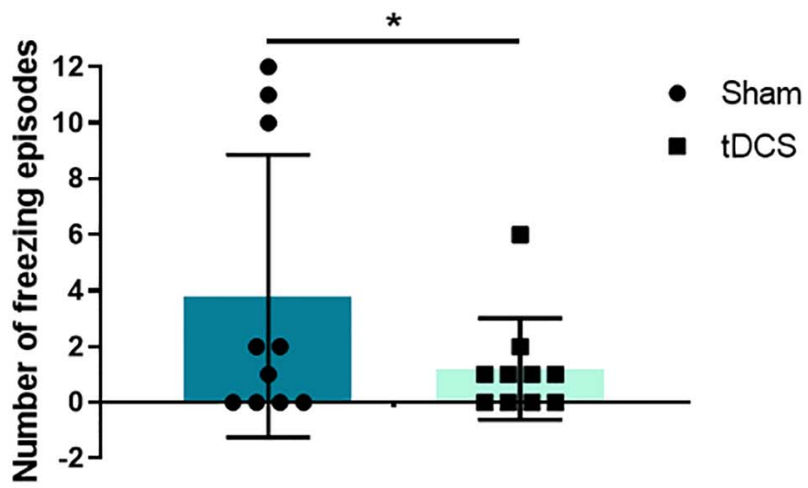

B

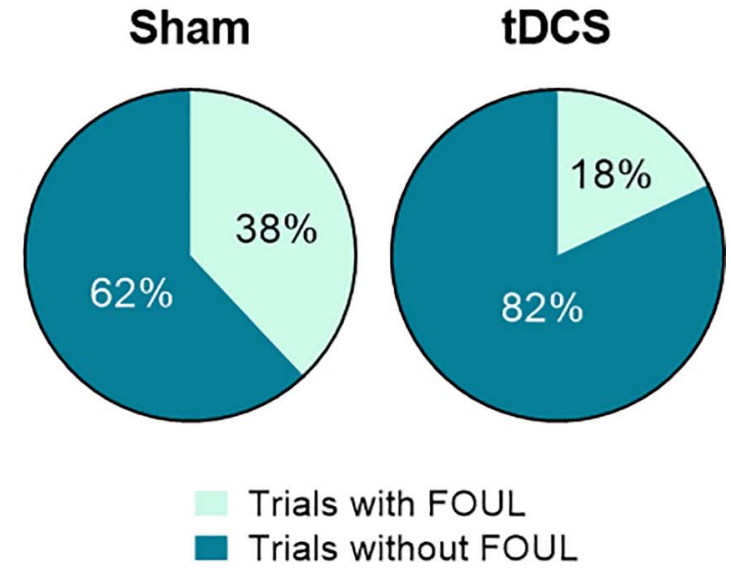

Fig. 2. Upper limb freezing (FOUL) episodes for patients with Parkinson's disease. (A) Number of FOUL episodes during sham stimulation and tDCS (black dots and squares, respectively). Data are presented as group means ( \pm standard deviation) as well as individual data points. (B) Relative number of trials with and without FOUL episodes. "Indicates p-value $<0.05$ (post hoc test).
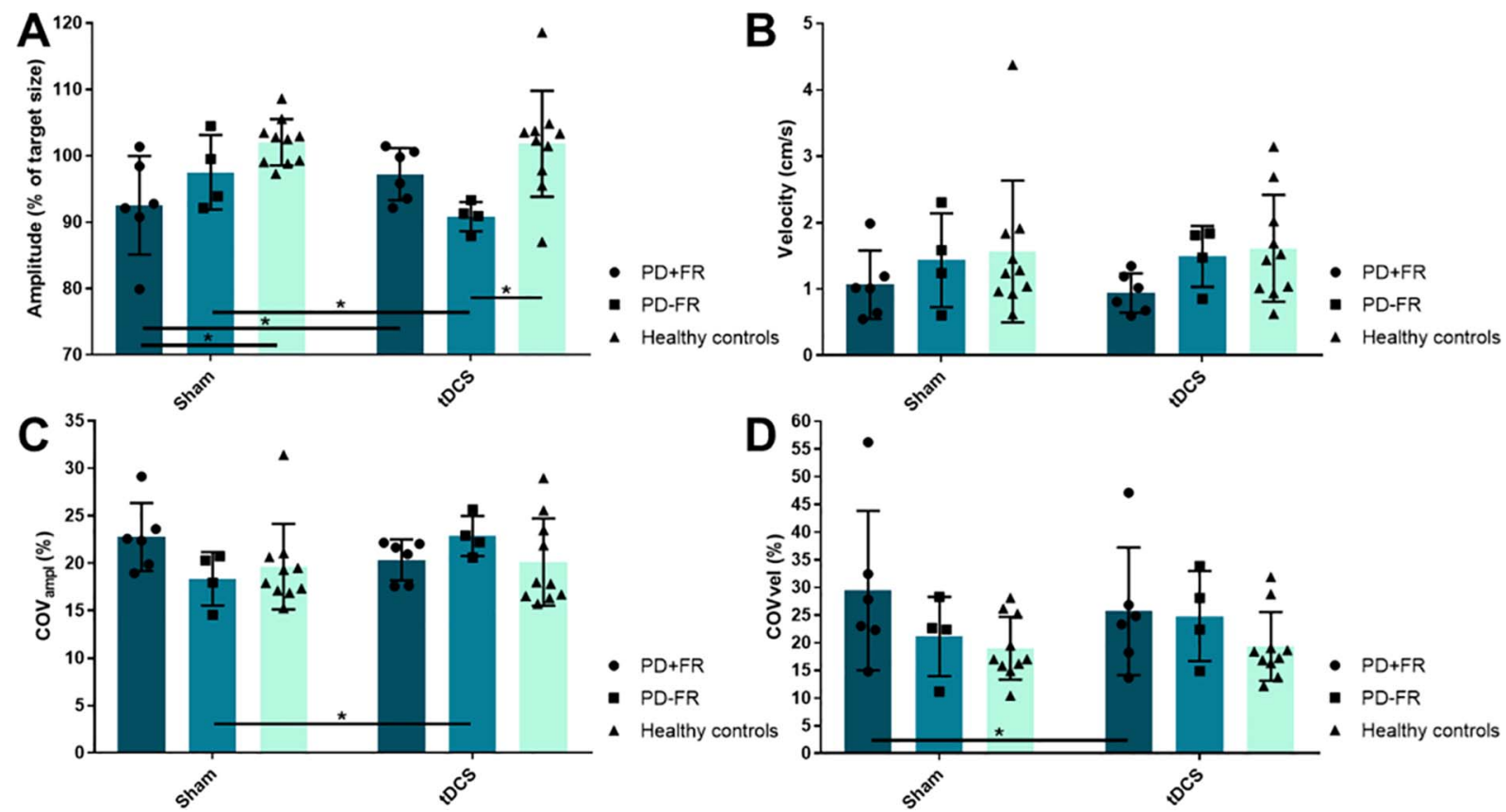

Fig. 3. Writing performance for patients with freezing (PD + FR), patients without freezing (PD-FR) and healthy controls (black dots, squares and triangles, respectively). Data are presented as group means ( \pm standard deviation) as well as individual data points. (A) Writing amplitude (\% of target size), (B) Writing velocity $(\mathrm{cm} / \mathrm{s}),(\mathrm{C})$ Coefficient of variation of the writing amplitude (\%), (D) Coefficient of variation of the writing velocity (\%). "Indicates p-value < 0.05 (post hoc tests).

significantly smaller amplitudes in the small and increasing parts of the task compared to healthy participants (both $\mathrm{p}<0.0005$ ). There were no significant three-way or Group $\times$ Condition interactions for writing amplitude and no significant interactions for the writing velocity, $\mathrm{COV}_{\mathrm{ampl}}, \mathrm{COV}_{\mathrm{vel}}$ and horizontal distance of both the maxima and minima. A complete overview of results is provided in the appendix Table A.2.

\subsubsection{Exploratory analysis in patients with and without freezing in daily life}

Fig. 3 shows the results of models comparing PD + FR, PD-FR and healthy controls. A Group x Condition $(F(2119)=7.350$, $\mathrm{p}=0.001$ ) interaction was demonstrated for writing amplitude and is illustrated by Fig. 3A. Post hoc tests comparing amplitudes during tDCS versus sham, showed a significant improvement during tDCS for PD + FR ( $\mathrm{p}=0.014)$, and a reduction in amplitude for PD-FR ( $p=0.004)$. In addition, significantly smaller writing amplitudes compared to healthy controls were found for PD + FR during sham $(\mathrm{p}=0.004)$ and for PD-FR during tDCS $(\mathrm{p}=0.004)($ Fig. $3 A)$. For the writing amplitude the Group $\times$ Size interaction was also significant $(\mathrm{F}(6119)=3.121, \mathrm{p}=0.007)$. Post hoc analysis revealed that both PD $+\mathrm{FR}$ and PD-FR wrote significantly 
smaller in the small and increasing parts of the task compared to healthy control subjects (resp. PD + FR: $p=0.003$ and $p=0.002$; PD-FR: $p=0.001$ and $p=0.039$ ). No significant interactions were found for writing velocity (Fig. 3B) and horizontal distances of the maxima and minima. Both the analysis of the $\mathrm{COV}_{\mathrm{ampl}}$ and $\mathrm{COV}_{\mathrm{vel}}$ revealed significant Group $\times$ Condition interactions (resp. $\mathrm{F}$ $(2119)=4.422, \mathrm{p}=0.0014$ and $\mathrm{F}(2119)=3.313, \mathrm{p}=0.040)$. Post hoc analysis showed a significant higher $\mathrm{COV}_{\mathrm{ampl}}$ for PD-FR $(\mathrm{p}=0.014)$ and a significant lower $\mathrm{COV}_{\mathrm{vel}}$ for PD + FR $(\mathrm{p}=0.046)$ during tDCS compared to sham (Fig. 3C and 3D).

The sub analysis within the PD group (i.e. PD + FR and PD-FR), with LED values as a covariate as PD + FR had higher values than $\mathrm{PD}-\mathrm{FR}$, revealed a significant Group $\times$ Condition $\times$ Size interaction for $\operatorname{COV}_{\mathrm{ampl}}(\mathrm{F}(3,42)=3.342, \mathrm{p}=0.028)$. Post hoc analysis for each part separately showed only for the large parts of the task a significant reduction and thus improvement in $\mathrm{COV}_{\mathrm{ampl}} \mathrm{during}_{\mathrm{tDCS}}$ compared to sham for PD + FR. The complete set of results is provided in the appendix Table A.3.

\subsection{Correlations}

Correlation analysis revealed that the number of FOUL episodes was significantly associated with a higher age in both PD patients and healthy controls during sham only (resp. $r_{s}=0.802, p=0.005$ and $r_{s}=0.701, p=0.024$ ). There were no other significant correlations between clinical characteristics and writing outcomes for both PD patients and healthy control subjects.

Additional correlation analysis for patient characteristics showed that during sham only the occurrence of FOUL episodes was significantly associated with LED values $\left(r_{s}=0.640, p=0.046\right)$ and with NFOG-Q scores $\left(r_{s}=0.645, p=0.044\right)$, indicating that patients with more FOG also had more FOUL during the funnel task. For stroke characteristics, the amplitude during tDCS only was significantly associated with NGF-Q scores $\left(r_{s}=0.806, p=0.005\right)$.

\section{Discussion}

The present sham-controlled pilot study investigated whether one session of concurrent M1-tDCS during motor execution affected upper limb freezing and writing sequential up-and-down strokes in patients with PD compared to healthy controls. The study used a funnel-task paradigm previously validated to elicit FOUL episodes (Heremans et al., 2015). We found a significant reduction in the number of FOUL episodes during tDCS compared to sham stimulation in PD. No significant benefits of tDCS were found for the complete PD and healthy control groups when analyzing stroke amplitude, velocity and variability outside the freezing episodes. However, a subgroup analysis in the patients who reported to have freezing episodes in daily life showed improvements in amplitude and writing variability during the non-freezing parts of the trajectory as well. On the contrary, writing performance of non-freezers was worse during tDCS compared to sham stimulation.

\subsection{Upper limb freezing and writing performance in Parkinson's disease}

Of the ten included PD patients, eight experienced at least one freezing episode in our funnel paradigm (Table 2), even though they were all optimally medicated. The discrepancy between self-reported and actual occurrence of FOUL has been reported repeatedly in FOG (Barthel, Mallia, Debu, Bloem, \& Ferraye, 2016). In the case of FOUL, perception of these problems in daily life is less marked than freezing when walking, explaining the incongruity. Most FOUL episodes were found in the small parts $(0.6 \mathrm{~cm})$ of the task, which is in line with a previous study (Heremans et al., 2015). Other work also showed small amplitudes during bimanual tasks and gait when patients were off-medication, resulting in reduced coordination patterns and increased frequency of freezing episodes (Chee, Murphy, Danoudis, Georgiou-Karistianis, \& Iansek, 2009; Nieuwboer, Vercruysse et al., 2009; Pereira, Gobbi, \& Almeida, 2016; Vercruysse, Spildooren et al., 2012; Williams, Peterson, Ionno, Pickett, \& Earhart, 2013). Together, these results confirm that amplitude reduction during automatic movements plays a role in the occurrence of freezing in different effectors. Decreases in amplitude probably augment the difficulty of a task by increased accuracy constraints, pushing patients to exceed the limits of their motor capacity, resulting in a motor breakdown. Decreases in amplitude may also augment the difficulty of a task (i.e. increased accuracy constraint) and thus increase the necessity to shift from automatic control of a movement to more cognitively controlled performance. Previous findings showed that writing amplitude was overall reduced when comparing PD patients with and without freezing of gait (Heremans et al., 2016). Moreover, impaired writing in freezers was associated with reduced effective connectivity in the visuomotor integration system of the brain (Nackaerts, Nieuwboer et al., 2017). The present pilot study did not find a difference in stroke amplitude nor horizontal distance of the strokes outside the freezing episodes between PD + FR and PD-FR, which may reflect the difference between producing up- and down-strokes and actual writing, the latter being more accuracy-demanding and driven by cognitive control (Nackaerts, Nieuwboer et al., 2017). Also, earlier work compared groups with and without self-reported freezing of gait, whereas here we contrasted cohorts with self-reported non-gait freezing. However, FOUL episodes proved to be associated with the severity of gait freezing (i.e. NFOG-Q scores), similarly to what was established before and supporting the idea that shared mechanisms between these phenomena may be at play (Heremans et al., 2015; Nieuwboer et al., 2009; Vercruysse, Devos et al., 2012; Vercruysse, Gilat et al., 2014; Williams et al., 2013; Ziv et al., 1999). It also implies that those who did report FOG in daily life may be more susceptible to FOUL. Interestingly, we found three freezing episodes (i.e. two during sham and one during tDCS) in two healthy control subjects. The occurrence of FOUL episodes in healthy participants was also found in the study of Heremans et al. in the same task as well as during finger tapping (Heremans et al., 2015; Ziv et al., 1999). A possible explanation may be found in the normal age-related decline in the basal ganglia (Coxon et al., 2010; Serbruyns et al., 2015). Indeed, our correlation analysis showed that higher age across all subjects proved to be associated with an increased probability of FOUL. 


\subsection{Effects of tDCS on freezing episodes and non-freezing writing trajectories}

The finding that M1-tDCS can reduce the number of FOUL episodes is in agreement with a study that measured the effects of tDCS on freezing during gait performance, hypothesized to enhance cortical compensatory mechanisms (Valentino et al., 2014). Freezing is a complex phenomenon and the failing of several brain networks has been shown to be involved (Snijders et al., 2016). Imaging during successful performance of a bimanual finger-tapping paradigm, demonstrated reduced activity in cortical frontal areas and increased subcortical activity in patients with freezing compared to those without and healthy controls. During FOUL episodes, the same study observed a cortical hyper-activity (i.e. right supplementary motor area, dorsal premotor cortex and M1, and left prefrontal cortex) associated with subcortical hypo-activity (i.e. bilateral pallidum and putamen) (Vercruysse, Spildooren et al., 2014). Although only a small current is delivered, anodal tDCS can increase the neuronal firing rate of the stimulated area resulting in excitability alterations as demonstrated in animal models (Keuters et al., 2015; Li et al., 2015; Morrell, 1961; Orban de Xivry \& Shadmehr, 2014). Constant stimulation of M1 during task performance in patients with freezing may normalize cortical activity, by preventing hyper-activity in M1 and other connected areas during more cognitively controlled movements (i.e. prevention of FOUL during the difficult parts of the task). In addition, tDCS may possibly indirectly influence subcortical areas via modulation of functional connectivity of cortico-striatal circuits (Hess, 2013; Li et al., 2015; Nonnekes et al., 2014; Polania, Nitsche, \& Paulus, 2011). Animal studies suggest an induction of dopamine release via the glutamatergic cortico-striatal pathways after cortical stimulation (Li, Tian, Qian, Yu, \& Jiang, 2011; Lu et al., 2015; Tanaka et al., 2013; Whitton, 1997). Interestingly, in the current study opposite effects of tDCS on stroke performance were found for patients reporting freezing episodes in daily life and those who do not. Stimulation of M1 resulted in improvements in amplitude and writing variability for PD + FR whereas writing performance of PD-FR was worse during tDCS compared to sham. This may point to a variability of response, suggesting that tDCS induced a gain of excitability in patients prone to FOUL, which was absent in those without this inclination. Previously, it was shown that PD patients with increased disease severity showed greater tDCS-related improvements (Kaski et al., 2014). In our study, PD + FR and PD-FR were matched for disease severity, except for medication dose. This higher LED for PD + FR, also found in previous studies, may have masked the impact of greater disease progression in PD + FR (Ginis et al., 2017; Vercruysse, Devos et al., 2012).

Recent research suggests that other targets than M1 or bimodal non-invasive stimulation may be better in influencing the complex circuitry affected in freezing (Chang et al., 2017; Dagan et al., 2017; Lee et al., 2014). Cosentino and colleagues pointed to different effects of tDCS when targeting the M1 of the most- or less-affected hemisphere in PD. They found that only anodal tDCS applied to the most-affected hemisphere resulted in increased cortical excitability together with improved motor performance (Cosentino et al., 2017). Moreover, pairing tDCS to training of gait resulted in significantly greater benefit than the effects of tDCS and training as single therapy (Kaski et al., 2014). In the current study, tDCS was applied to the most-affected hemisphere whilst subjects were engaged in motor activity. The promising prevention of motor breakdown together with better maintenance of amplitude and coordination in a subgroup of patients, point to the possibility to use stimulation as an adjuvant tool during long-term training of gait and other repetitive motor tasks.

\subsection{Study limitations}

The beneficial effects of tDCS were generally in line with our expectations. However, the small sample size (i.e. 10 PD patients and 10 healthy control subjects) limits the generalizability of our findings and could have resulted in type II errors. Moreover, the order of the tasks during our intervention (i.e. writing sequences followed by execution of the funnel task) could have influenced our performance on the funnel task. Our results are therefore preliminary and further investigation is warranted. Subgroup analysis of patients with and without freezing consisted of even smaller groups. The sensitivity analysis was based on subgroups defined by the occurrence of freezing in daily life as assessed with the NGF-Q scores. This self-reported questionnaire proved highly predictive of FOG and was associated with writing parameters. However, the cutoff of this scale has not been validated before for subgroup determination.

We used a cross-over design controlling for possible carry-over effects by incorporating a wash-out period of minimal 21 days. Considering the high variability of tDCS results (Buch et al., 2017; Horvath, Vogrin, Carter, Cook, \& Forte, 2016; Ziemann \& Siebner, 2015) as well as of freezing as a clinical phenomenon (Nutt et al., 2011), it is recommended to use parallel designs in future studies. Considering the tDCS application, higher intensities (e.g. $2 \mathrm{~mA}$ ) and longer stimulation durations may be more effective to enhance performance in PD (Boggio et al., 2006; Cuypers et al., 2013), although varying alterations in baseline excitability may also induce unpredictable responses (Buhmann et al., 2004; Kojovic et al., 2015).

\subsection{Conclusion}

This is the first study investigating the effects of motor performance combined with tDCS on upper limb freezing in PD. We found preliminary evidence for a beneficial effect of tDCS for reducing FOUL episodes. Differential effects for stroke size and variability were found for patients with and without freezing, suggesting that the latter might be more susceptible to tDCS. Our findings carve out directions for further research in that the variability of the response to neuro-stimulation proved subgroup-dependent in PD. The present results also justify future studies that test tDCS as a complementary tool for training programs aimed to reduce the core motor deficits of freezing. 


\section{Declaration of interest}

None.

\section{Acknowledgements}

We thank all participants for their commitment. We thank Ilke D'haese and Liesbet Van Gansen for their help in the analysis of the funnel task trials for the presence of upper limb freezing and Ir. Marc Beirinckx for development of the writing tablet and for providing technical support.

\section{Funding}

The Research Foundation Flanders (FWO) supported this study; SB is a research assistant and EH is a postdoctoral researcher of the FWO. EN is a postdoctoral researcher funded by the KU Leuven research fund [Grant No. PDM/17/197]. MPP is a postdoctoral researcher funded by the Brazilian National Council for Scientific and Technological Development (CNPq) [Grant No.: 232879/20141]. All funders had no role in study design, data collection and analysis, decision to publish, or preparation of the manuscript.

\section{Appendices}

See Table A.1, Table A.2, Table A.3.

Table A.1

The absolute number of upper limb freezing episodes per part of the task for PD patients and healthy controls.

\begin{tabular}{|c|c|c|c|c|c|c|}
\hline & \multicolumn{3}{|c|}{$\mathrm{PD}(\mathrm{N}=10)$} & \multicolumn{3}{|c|}{$\mathrm{HC}(\mathrm{N}=10)$} \\
\hline & Sham & tDCS & $\Delta_{\text {tDCS-sham }}$ & Sham & $\mathrm{tDCS}$ & $\Delta_{\text {tDCS-sham }}$ \\
\hline Small $(0.6 \mathrm{~cm})^{*, I}$ & 20 & 4 & -16 & 0 & 1 & 1 \\
\hline Large $(2.0 \mathrm{~cm})^{\mathrm{I}}$ & 0 & 2 & 2 & 0 & 0 & 0 \\
\hline Decreasing $(2.0-0.6 \mathrm{~cm})$ & 11 & 1 & -10 & 2 & 0 & -2 \\
\hline Increasing $(0.6-2.0 \mathrm{~cm})$ & 7 & 5 & -2 & 0 & 0 & 0 \\
\hline
\end{tabular}

Abbreviations: $\Delta=$ difference in number of upper limb freezing episodes during tDCS and sham stimulation; HC $=$ healthy control subjects; PD $=$ patients with Parkinson's disease.

* Groups (i.e. PD patients and healthy controls) significantly different at p-value $<0.05$.

${ }^{\mathrm{I}}$ Sizes (i.e. small and large) significantly different at p-value $<0.05$ for PD patients.

Table A.2

Writing performance outside the freezing episodes per part of the task for PD patients and healthy controls.

\begin{tabular}{|c|c|c|c|c|c|c|}
\hline & \multicolumn{3}{|l|}{$\mathrm{PD}(\mathrm{N}=10)$} & \multicolumn{3}{|l|}{$\mathrm{HC}(\mathrm{N}=10)$} \\
\hline & Sham & $\mathrm{tDCS}$ & $\Delta_{\text {tDCS-sham }}$ & Sham & $\mathrm{tDCS}$ & $\Delta_{\text {tDCS-sham }}$ \\
\hline \multicolumn{7}{|l|}{ Amplitude (\%) } \\
\hline Small ${ }^{*}$ & $95.4( \pm 6.8)$ & $94.9( \pm 5.0)$ & $-0,5$ & $106.7( \pm 7.3)$ & $107.6( \pm 10.4)$ & 0,9 \\
\hline Large & $89.1( \pm 5.7)$ & $91.4( \pm 3.2)$ & 2,3 & $95.7( \pm 2.2)$ & $94.3( \pm 6.8)$ & $-1,4$ \\
\hline Decreasing & $99.2( \pm 13.1)$ & $95.8( \pm 12.2)$ & $-3,4$ & $98.0( \pm 5.1)$ & $100.6( \pm 7.4)$ & 2,6 \\
\hline Increasing & $94.5( \pm 6.1)$ & $96.7( \pm 6.7)$ & 2,2 & $107.7( \pm 5.1)$ & $104.8( \pm 11.6)$ & $-2,9$ \\
\hline \multicolumn{7}{|c|}{ Velocity $(\mathrm{cm} / \mathrm{s})$} \\
\hline Small & $1.8( \pm 0.8)$ & $1.7( \pm 0.9)$ & $-0,1$ & $2.1( \pm 1.2)$ & $2.1( \pm 1.0)$ & 0 \\
\hline Large & $0.9( \pm 0.5)$ & $0.8( \pm 0.2)$ & $-0,1$ & $1.2( \pm 1.0)$ & $1.2( \pm 0.7)$ & $\mathbf{0}$ \\
\hline Decreasing & $1.2( \pm 0.6)$ & $1.1( \pm 0.5)$ & $-0,1$ & $1.6( \pm 1.1)$ & $1.6( \pm 0.8)$ & 0 \\
\hline Increasing & $1.1( \pm 0.5)$ & $1.0( \pm 0.4)$ & $-0,1$ & $1.4( \pm 1.0)$ & $1.5( \pm 0.8)$ & 0,1 \\
\hline \multicolumn{7}{|l|}{$\mathrm{COV}_{\mathrm{ampl}}(\%)$} \\
\hline Small & $15.1( \pm 6.2)$ & $13.6( \pm 3.6)$ & $-1,5$ & $16.6( \pm 14.0)$ & $16.0( \pm 8.8)$ & $-0,6$ \\
\hline Large & $11.2( \pm 5.6)$ & $9.2( \pm 3.6)$ & -2 & $6.1( \pm 2.7)$ & $8.1( \pm 6.4)$ & 2 \\
\hline Decreasing & $28.2( \pm 5.6)$ & $31.2( \pm 6.6)$ & 3 & $27.8( \pm 3.0)$ & $27.7( \pm 2.1)$ & $-0,1$ \\
\hline Increasing & $29.6( \pm 3.0)$ & $31.4( \pm 3.8)$ & 1,8 & $28.0( \pm 2.9)$ & $28.6( \pm 4.6)$ & 0,6 \\
\hline \multicolumn{7}{|l|}{$\mathrm{COV}_{\text {vel }}(\%)$} \\
\hline Small & $24.6( \pm 12.1)$ & $22.6( \pm 7.3)$ & -2 & $19.9( \pm 7.5)$ & $17.1( \pm 5.4)$ & $-2,8$ \\
\hline Large & $21.0( \pm 17.3)$ & $19.3( \pm 15.2)$ & $-1,7$ & $13.6( \pm 4.7)$ & $14.5( \pm 6.1)$ & 0,9 \\
\hline Decreasing & $29.1( \pm 14.7)$ & $25.8( \pm 10.7)$ & $-3,3$ & $20.9( \pm 4.9)$ & $21.6( \pm 6.9)$ & 0,7 \\
\hline Increasing & $29.8( \pm 8.5)$ & $33.6( \pm 17.9)$ & 3,8 & $21.8( \pm 8.3)$ & $24.0( \pm 10.9)$ & 2,2 \\
\hline
\end{tabular}


Table A.2 (continued)

\begin{tabular}{|c|c|c|c|c|c|c|}
\hline & \multicolumn{3}{|l|}{$\mathrm{PD}(\mathrm{N}=10)$} & \multicolumn{3}{|l|}{$\mathrm{HC}(\mathrm{N}=10)$} \\
\hline & Sham & $\mathrm{tDCS}$ & $\Delta_{\text {tDCS-sham }}$ & Sham & $\mathrm{tDCS}$ & $\Delta_{\text {tDCS-sham }}$ \\
\hline \multicolumn{7}{|c|}{ HorzDist $_{\text {Max }}(\mathrm{mm})$} \\
\hline Small & $1.8( \pm 0.6)$ & $1.8( \pm 0.7)$ & 0.1 & $2.0( \pm 0.4)$ & $1.9( \pm 0.5)$ & -0.1 \\
\hline Large & $3.0( \pm 1.3)$ & $2.4( \pm 0.7)$ & -0.6 & $2.4( \pm 0.6)$ & $2.2( \pm 0.8)$ & -0.2 \\
\hline Decreasing & $2.2( \pm 0.8$ & $2.4( \pm 0.7)$ & 0.2 & $2.2( \pm 0.5)$ & $2.0( \pm 0.6)$ & -0.2 \\
\hline Increasing & $2.1( \pm 0.8)$ & $2.1( \pm 0.9)$ & 0.0 & $2.3( \pm 0.6)$ & $2.2( \pm 0.7)$ & -0.1 \\
\hline \multicolumn{7}{|c|}{ HorzDist $_{\text {Min }}(\mathrm{mm})$} \\
\hline Small & $1.9( \pm 0.6)$ & $1.8( \pm 0.6)$ & -0.1 & $2.2( \pm 1.0)$ & $2.0( \pm 0.6)$ & -0.2 \\
\hline Large & $2.6( \pm 1.4)$ & $2.5( \pm 1.0)$ & -0.1 & $2.6( \pm 0.9)$ & $2.5( \pm 1.0)$ & -0.1 \\
\hline Decreasing & $2.3( \pm 0.8)$ & $2.2( \pm 0.7)$ & 0.0 & $2.5( \pm 1.2)$ & $2.5( \pm 1.0)$ & -0.1 \\
\hline Increasing & $1.9( \pm 0.8)$ & $2.3( \pm 1.4)$ & 0.4 & $2.5( \pm 1.0)$ & $2.0( \pm 0.5)$ & -0.5 \\
\hline
\end{tabular}

Abbreviations: $\Delta=$ difference in writing performance during tDCS and sham stimulation; $\mathrm{HC}=$ healthy control subjects; HorzDist $\mathrm{max}_{\mathrm{m}}=$ horizontal distance between maxima; HorzDist ${ }_{\min }=$ horizontal distance between minima; PD = patients with Parkinson's disease.

Results are presented as group means ( \pm standard deviation).

* Groups (i.e. PD patients and healthy controls) significantly different at p-value $<0.05$.

Table A.3

Writing performance outside the freezing episodes per part of the task for PD patients with and without freezing in daily life.

\begin{tabular}{|c|c|c|c|c|c|c|}
\hline & \multicolumn{3}{|c|}{$P D+F R(N=6)$} & \multicolumn{3}{|l|}{ PD-FR $(\mathrm{N}=4)$} \\
\hline & Sham & $\mathrm{tDCS}$ & $\Delta_{\text {tDCS-sham }}$ & Sham & tDCS & $\Delta_{\text {tDCS-sham }}$ \\
\hline \multicolumn{7}{|c|}{ Amplitude $(\%)^{\Delta}$} \\
\hline Small & $95.1( \pm 7.3)$ & $97.2( \pm 4.3)$ & 2,1 & $95.7( \pm 7.2)$ & $91.4( \pm 4.2)$ & $-4,3$ \\
\hline Large & $87.4( \pm 7.0)$ & $93.0( \pm 2.7)$ & 5,6 & $91.5( \pm 1.4)$ & $89.0( \pm 2.6)$ & $-2,5$ \\
\hline Decreasing & $95.9( \pm 12.7)$ & $101.2(13.2)$ & 5,3 & $104.1( \pm 13.8)$ & $87.6( \pm 2.1)$ & $-16,5$ \\
\hline Increasing & $91.7( \pm 5.9)$ & $97.5( \pm 8.7)$ & 5,8 & $98.6( \pm 4.2)$ & $95.4( \pm 2.6)$ & $-3,2$ \\
\hline \multicolumn{7}{|c|}{ Velocity $(\mathrm{cm} / \mathrm{s})$} \\
\hline Small & $1.5( \pm 0.6)$ & $1.4( \pm 0.6)$ & $-0,1$ & $2.2( \pm 1.1)$ & $2.3( \pm 0.9)$ & 0,1 \\
\hline Large & $0.8( \pm 0.6)$ & $0.7( \pm 0.2)$ & $-0,1$ & $1.0( \pm 0.5)$ & $0.9( \pm 0.2)$ & $-0,1$ \\
\hline Decreasing & $1.1( \pm 0.6)$ & $0.9( \pm 0.4)$ & $-0,2$ & $1.3( \pm 0.7)$ & $1.4( \pm 0.3)$ & 0,1 \\
\hline Increasing & $0.9( \pm 0.4)$ & $0.8( \pm 0.2)$ & $-0,1$ & $1.3( \pm 0.7)$ & $1.3( \pm 0.4)$ & 0 \\
\hline \multicolumn{7}{|l|}{$\mathrm{COV}_{\mathrm{ampl}}(\%)$} \\
\hline Small & $16.7( \pm 7.0)$ & $14.0( \pm 4.1)$ & $-2,7$ & $12.6( \pm 4.5)$ & $12.9( \pm 3.2)$ & 0,3 \\
\hline Large & $13.3( \pm 6.4)$ & $7.9( \pm 3.3)$ & $-5,4$ & $8.0( \pm 2.3)$ & $11.2( \pm 3.6)$ & 3,2 \\
\hline Decreasing & $30.7( \pm 2.0)$ & $27.7( \pm 5.8)$ & -3 & $24.5( \pm 7.5)$ & $36.4( \pm 3.5)$ & 11,9 \\
\hline Increasing & $30.3( \pm 3.6)$ & $31.8( \pm 4.1)$ & 1,5 & $28.4( \pm 1.8)$ & $30.9( \pm 4.0)$ & 2,5 \\
\hline \multicolumn{7}{|l|}{$\mathrm{COV}_{\text {vel }}(\%)$} \\
\hline Small & $28.4( \pm 14.4)$ & $24.1( \pm 8.7)$ & $-4,3$ & $19.0( \pm 5.0)$ & $20.4(4.8)$ & 1,4 \\
\hline Large & $25.2( \pm 21.5)$ & $23.1( \pm 18.9)$ & $-2,1$ & $14.7( \pm 6.2)$ & $13.6( \pm 5.4)$ & $-1,1$ \\
\hline Decreasing & $32.8( \pm 17.5)$ & $21.0( \pm 8.6)$ & $-11,8$ & $23.5( \pm 8.3)$ & $33.0( \pm 10.2)$ & 9,5 \\
\hline Increasing & $31.4( \pm 7.0)$ & $34.4( \pm 19.9)$ & 3 & $27.3( \pm 11.0)$ & $32.3( \pm 17.2)$ & 5 \\
\hline \multicolumn{7}{|c|}{ HorzDist $_{\text {Max }}(\mathrm{mm})$} \\
\hline Small & $2.0( \pm 0.4)$ & $2.2( \pm 0.6)$ & 0.2 & $1.4( \pm 0.6)$ & $1.3( \pm 0.4)$ & -0.1 \\
\hline Large & $3.4( \pm 1.2)$ & $2.6( \pm 0.9)$ & -0.7 & $2.5( \pm 1.4)$ & $2.0( \pm 0.2)$ & -0.4 \\
\hline Decreasing & $2.5( \pm 1.0)$ & $2.6( \pm 0.6)$ & 0.1 & $1.9( \pm 0.3)$ & $2.2( \pm 0.9)$ & 0.3 \\
\hline Increasing & $2.6( \pm 0.7)$ & $2.4( \pm 1.1)$ & -0.2 & $1.4( \pm 0.3)$ & $1.6( \pm 0.2)$ & 0.2 \\
\hline \multicolumn{7}{|c|}{ HorzDist $_{\text {Min }}(\mathrm{mm})$} \\
\hline Small & $2.1( \pm 0.5)$ & $2.1( \pm 0.5)$ & 0.0 & $1.5( \pm 0.7)$ & $1.3( \pm 0.4)$ & -0.3 \\
\hline Large & $3.3( \pm 1.3)$ & $2.7( \pm 0.8)$ & -0.7 & $1.5( \pm 0.3)$ & $2.3( \pm 1.2)$ & 0.8 \\
\hline Decreasing & $2.6( \pm 0.6)$ & $2.4( \pm 0.7)$ & -0.1 & $1.9( \pm 1.0)$ & $1.9( \pm 0.7)$ & 0.0 \\
\hline Increasing & $2.1( \pm 0.9)$ & $2.6( \pm 1.7)$ & 0.5 & $1.6( \pm 0.5)$ & $1.7( \pm 0.9)$ & 0.1 \\
\hline
\end{tabular}

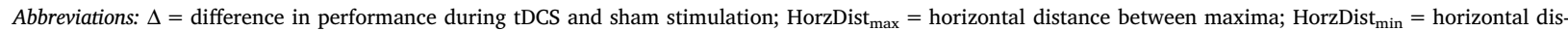
tance between minima; PD + FR = Parkinson patients with freezing; PD-FR = Parkinson patients without freezing.

Results are presented as group means ( \pm standard deviation).

* Results for condition (i.e. sham and tDCS) significantly different at p-value $<0.05$ for PD + FR. 


\section{References}

Barthel, C., Mallia, E., Debu, B., Bloem, B. R., \& Ferraye, M. U. (2016). The practicalities of assessing freezing of gait. Journal of Parkinson's Disease, 6, 667-674. Benninger, D. H., \& Hallett, M. (2015). Non-invasive brain stimulation for Parkinson's disease: Current concepts and outlook 2015. NeuroRehabilitation, 37, 11-24. Benninger, D. H., Lomarev, M., Lopez, G., Wassermann, E. M., Li, X., Considine, E., \& Hallett, M. (2010). Transcranial direct current stimulation for the treatment of Parkinson's disease. Journal of Neurology, Neurosurgery, and Psychiatry, 81, 1105-1111.

Bidet-Ildei, C., Pollak, P., Kandel, S., Fraix, V., \& Orliaguet, J. P. (2011). Handwriting in patients with Parkinson disease: Effect of L-dopa and stimulation of the subthalamic nucleus on motor anticipation. Human Movement Science, 30, 783-791.

Boggio, P. S., Ferrucci, R., Rigonatti, S. P., Covre, P., Nitsche, M., Pascual-Leone, A., \& Fregni, F. (2006). Effects of transcranial direct current stimulation on working memory in patients with Parkinson's disease. Journal of the Neurological Sciences, 249, 31-38.

Broderick, M. P., Van Gemmert, A. W., Shill, H. A., \& Stelmach, G. E. (2009). Hypometria and bradykinesia during drawing movements in individuals with Parkinson's disease. Experimental Brain Research, 197, 223-233.

Broeder, S., Nackaerts, E., Heremans, E., Vervoort, G., Meesen, R., Verheyden, G., \& Nieuwboer, A. (2015). Transcranial direct current stimulation in Parkinson's disease: Neurophysiological mechanisms and behavioral effects. Neuroscience \& Biobehavioral Reviews, 57, $105-117$.

Buch, E. R., Santarnecchi, E., Antal, A., Born, J., Celnik, P. A., Classen, J., ... Cohen, L. G. (2017). Effects of tDCS on motor learning and memory formation: A consensus and critical position paper. Clinical Neurophysiology, 128, 589-603.

Buhmann, C., Gorsler, A., Baumer, T., Hidding, U., Demiralay, C., Hinkelmann, K., ... Munchau, A. (2004). Abnormal excitability of premotor-motor connections in de novo Parkinson's disease. Brain, 127, 2732-2746.

Chang, W. H., Kim, M. S., Park, E., Cho, J. W., Youn, J., Kim, Y. K., \& Kim, Y. H. (2017). Effect of dual-mode and dual-site noninvasive brain stimulation on freezing of gait in patients with parkinson disease. Archives of Physical Medicine and Rehabilitation, 98, 1283-1290.

Chee, R., Murphy, A., Danoudis, M., Georgiou-Karistianis, N., \& Iansek, R. (2009). Gait freezing in Parkinson's disease and the stride length sequence effect interaction. Brain, 132, 2151-2160.

Cosentino, G., Valentino, F., Todisco, M., Alfonsi, E., Davi, R., Savettieri, G., ... Brighina, F. (2017). Effects of more-affected vs. less-affected motor cortex tDCS in Parkinson's disease. Frontiers in Human Neuroscience, 11, 309.

Coxon, J. P., Goble, D. J., Van Impe, A., De Vos, J., Wenderoth, N., \& Swinnen, S. P. (2010). Reduced basal ganglia function when elderly switch between coordinated movement patterns. Cerebral Cortex, 20, 2368-2379.

Cuypers, K., Leenus, D. J., van den Berg, F. E., Nitsche, M. A., Thijs, H., Wenderoth, N., \& Meesen, R. L. (2013). Is motor learning mediated by tDCS intensity? PLoS One, 8, e67344.

Dagan, M., Herman, T., Mirelman, A., Giladi, N., \& Hausdorff, J. M. (2017). The role of the prefrontal cortex in freezing of gait in Parkinson's disease: Insights from a deep repetitive transcranial magnetic stimulation exploratory study. Experimental Brain Research, 235, 2463-2472.

Elsner, B., Kugler, J., Pohl, M., \& Mehrholz, J. (2016). Transcranial direct current stimulation (tDCS) for idiopathic Parkinson's disease. The Cochrane Database of Systematic Reviews, 7, CD010916.

Ferrucci, R., Mameli, F., Ruggiero, F., \& Priori, A. (2016). Transcranial direct current stimulation as treatment for Parkinson's disease and other movement disorders. Basal Ganglia, 6, 53-61.

Folstein, M. F., Folstein, S. E., \& McHugh, P. R. (1975). "Mini-Mental State" A practical method for grading the cognitive state of patients for the clinician. Journal of Psychiatric Research, 12, 189-198.

Fregni, F., Boggio, P. S., Santos, M. C., Lima, M., Vieira, A. L., Rigonatti, S. P., ... Pascual-Leone, A. (2006). Noninvasive cortical stimulation with transcranial direct current stimulation in Parkinson's disease. Movement Disorders, 21, 1693-1702.

Galea, J. M., \& Celnik, P. (2009). Brain polarization enhances the formation and retention of motor memories. Journal of Neurophysiology, 102, 294-301.

Gandiga, P. C., Hummel, F. C., \& Cohen, L. G. (2006). Transcranial DC stimulation (tDCS): A tool for double-blind sham-controlled clinical studies in brain stimulation. Clinical Neurophysiology, 117, 845-850.

Giladi, N. (2008). Medical treatment of freezing of gait. Movement Disorder, 23(Suppl 2), S482-488.

Ginis, P., Heremans, E., Ferrari, A., Bekkers, E. M. J., Canning, C. G., \& Nieuwboer, A. (2017). External input for gait in people with Parkinson's disease with and without freezing of gait: One size does not fit all. Journal of Neurology, 264, 1488-1496.

Goetz, C. G., Tilley, B. C., Shaftman, S. R., Stebbins, G. T., Fahn, S., Martinez-Martin, P., ... Movement Disorder Society UPDRS Revision Task Force (2008). Movement disorder society-sponsored revision of the Unified Parkinson's Disease Rating Scale (MDS-UPDRS): Scale presentation and clinimetric testing results. Movement Disorders, 23, 2129-2170.

Goodwill, A. M., Lum, J. A. G., Hendy, A. M., Muthalib, M., Johnson, L., Albein-Urios, N., \& Teo, W. P. (2017). Using non-invasive transcranial stimulation to improve motor and cognitive function in Parkinson's disease: A systematic review and meta-analysis. Scientific Reports, 7, 14840.

Heremans, E., Nackaerts, E., Broeder, S., Vervoort, G., Swinnen, S. P., \& Nieuwboer, A. (2016). Handwriting impairments in people with Parkinson's disease and freezing of gait. Neurorehabilitation and Neural Repair, 30, 911-919.

Heremans, E., Nackaerts, E., Vervoort, G., Vercruysse, S., Broeder, S., Strouwen, C., ... Nieuwboer, A. (2015). Amplitude manipulation evokes upper limb freezing during handwriting in patients with Parkinson's disease with freezing of gait. PLoS One, 10, e0142874.

Hess, C. W. (2013). Modulation of cortical-subcortical networks in Parkinson's disease by applied field effects. Frontiers in Human Neuroscience, 7 , 565.

Hoehn, M. M., \& Yahr, M. D. (1967). Parkinsonism: Onset, progression and mortality. Neurology, 17, 427-442.

Horvath, J. C., Vogrin, S. J., Carter, O., Cook, M. J., \& Forte, J. D. (2016). Effects of a common transcranial direct current stimulation (tDCS) protocol on motor evoked potentials found to be highly variable within individuals over 9 testing sessions. Experimental Brain Research, 234, $2629-2642$.

Hughes, A. J., Daniel, S. E., Kilford, L., \& Lees, A. J. (1992). Accuracy of clinical diagnosis of idiopathic Parkinson's disease: A clinico-pathological study of 100 cases. Journal of Neurology, Neurosurgery \& Psychiatry, 55, 181-184.

Kaski, D., Dominguez, R. O., Allum, J. H., Islam, A. F., \& Bronstein, A. M. (2014). Combining physical training with transcranial direct current stimulation to improve gait in Parkinson's disease: A pilot randomized controlled study. Clinical Rehabilitation, 28, 1115-1124.

Keuters, M. H., Aswendt, M., Tennstaedt, A., Wiedermann, D., Pikhovych, A., Rotthues, S., ... Rueger, M. A. (2015). Transcranial direct current stimulation promotes the mobility of engrafted NSCs in the rat brain. NMR in Biomedicine, 28, 231-239.

Kim, M. S., Chang, W. H., Cho, J. W., Youn, J., Kim, Y. K., Kim, S. W., \& Kim, Y. H. (2015). Efficacy of cumulative high-frequency rTMS on freezing of gait in Parkinson's disease. Restorative Neurology and Neuroscience, 33, 521-530.

Kojovic, M., Kassavetis, P., Bologna, M., Parees, I., Rubio-Agusti, I., Berardelli, A., ... Bhatia, K. P. (2015). Transcranial magnetic stimulation follow-up study in early Parkinson's disease: A decline in compensation with disease progression? Movement Disorders, 30, 1098-1106.

Lange, K. W., Mecklinger, L., Walitza, S., Becker, G., Gerlach, M., Naumann, M., \& Tucha, O. (2006). Brain dopamine and kinematics of graphomotor functions. Human Movement Science, 25, 492-509.

Lee, S. Y., Kim, M. S., Chang, W. H., Cho, J. W., Youn, J. Y., \& Kim, Y. H. (2014). Effects of repetitive transcranial magnetic stimulation on freezing of gait in patients with Parkinsonism. Restorative Neurology and Neuroscience, 32, 743-753.

Li, H., Lei, X., Yan, T., Li, H., Huang, B., Li, L., ... Hu, X. (2015). The temporary and accumulated effects of transcranial direct current stimulation for the treatment of advanced Parkinson's disease monkeys. Scientific Reports, 5, 12178.

Li, Y., Tian, X., Qian, L., Yu, X., \& Jiang, W. (2011). Anodal transcranial direct current stimulation relieves the unilateral bias of a rat model of Parkinson's disease. Conference of the IEEE Engineering in Medicine and Biology Society, 765-768.

Lu, C., Wei, Y., Hu, R., Wang, Y., Li, K., \& Li, X. (2015). Transcranial direct current stimulation ameliorates behavioral deficits and reduces oxidative stress in 1-methyl4-phenyl-1,2,3,6-tetrahydropyridine-induced mouse model of Parkinson's disease. Neuromodulation, 18, $442-446$ discussion 447.

Moore, S. T., MacDougall, H. G., \& Ondo, W. G. (2008). Ambulatory monitoring of freezing of gait in Parkinson's disease. Journal of Neuroscience Methods, 167, 340-348. 
Moreau, C., Ozsancak, C., Blatt, J. L., Derambure, P., Destee, A., \& Defebvre, L. (2007). Oral festination in Parkinson's disease: Biomechanical analysis and correlation with festination and freezing of gait. Movement Disorders, 22, 1503-1506.

Morrell, F. (1961). Effect of anodal polarization on the firing pattern of single cortical cells. Annals of the New York Academy of Sciences, 92, 860-876.

Nackaerts, E., Broeder, S., Pereira, M. P., Swinnen, S. P., Vandenberghe, W., Nieuwboer, A., \& Heremans, E. (2017). Handwriting training in Parkinson's disease: A trade-off between size, speed and fluency. PLoS One, 12, e0190223.

Nackaerts, E., Heremans, E., Vervoort, G., Smits-Engelsman, B. C., Swinnen, S. P., Vandenberghe, W., ... Nieuwboer, A. (2016). Relearning of writing skills in Parkinson's disease after intensive amplitude training. Movement Disorders, 31, 1209-1216.

Nackaerts, E., Nieuwboer, A., Broeder, S., Swinnen, S., Vandenberghe, W., \& Heremans, E. (2017). Altered effective connectivity contributes to micrographia in patients with Parkinson's disease and freezing of gait. Journal of Neurology.

Nasreddine, Z. S., Phillips, N. A., Bedirian, V., Charbonneau, S., Whitehead, V., Collin, I., ... Chertkow, H. (2005). The montreal cognitive assessment, MoCA: A brief screening tool for mild cognitive impairment. JAGS, 53, 695-699.

Nieuwboer, A., Rochester, L., Herman, T., Vandenberghe, W., Emil, G. E., Thomaes, T., \& Giladi, N. (2009). Reliability of the new freezing of gait questionnaire: Agreement between patients with Parkinson's disease and their carers. Gait Posture, 30, 459-463.

Nieuwboer, A., Vercruysse, S., Feys, P., Levin, O., Spildooren, J., \& Swinnen, S. (2009). Upper limb movement interruptions are correlated to freezing of gait in Parkinson's disease. The European Journal of Neuroscience, 29, 1422-1430.

Nonnekes, J., Arrogi, A., Munneke, M. A., van Asseldonk, E. H., Oude Nijhuis, L. B., Geurts, A. C., \& Weerdesteyn, V. (2014). Subcortical structures in humans can be facilitated by transcranial direct current stimulation. PLoS One, 9, e107731.

Nonnekes, J., Snijders, A. H., Nutt, J. G., Deuschl, G., Giladi, N., \& Bloem, B. R. (2015). Freezing of gait: A practical approach to management. The Lancet Neurology, 14, $768-778$.

Nutt, J. G., Bloem, B. R., Giladi, N., Hallett, M., Horak, F. B., \& Nieuwboer, A. (2011). Freezing of gait: Moving forward on a mysterious clinical phenomenon. The Lancet Neurology, 10, 734-744.

Oldfield, R. C. (1971). The assessment and analysis of handedness: The Edinburgh Inventory. Neuropsychologia, 9, 97-113.

Orban de Xivry, J. J., \& Shadmehr, R. (2014). Electrifying the motor engram: Effects of tDCS on motor learning and control. Experimental Brain Research, 232, 3379-3395.

Pereira, M. P., Gobbi, L. T., \& Almeida, Q. J. (2016). Freezing of gait in Parkinson's disease: Evidence of sensory rather than attentional mechanisms through muscle vibration. Parkinsonism \& Related Disorders, 29, 78-82.

Perez-Lloret, S., Negre-Pages, L., Damier, P., Delval, A., Derkinderen, P., Destee, A., ... Rascol, O. (2014). Prevalence, determinants, and effect on quality of life of freezing of gait in Parkinson disease. JAMA Neurology, 71, 884-890.

Polania, R., Nitsche, M. A., \& Paulus, W. (2011). Modulating functional connectivity patterns and topological functional organization of the human brain with transcranial direct current stimulation. Human Brain Mapping, 32, 1236-1249.

Ponsen, M. M., Daffertshofer, A., Wolters, E., Beek, P. J., \& Berendse, H. W. (2008). Impairment of complex upper limb motor function in de novo Parkinson's disease. Parkinsonism \& Related Disorders, 14, 199-204.

Poreh, A., \& Shye, S. (1998). Examination of the global and local features of the Rey Osterrieth complex figure using faceted smallest space analysis. The Clinical Neuropsychologist (Neuropsychology, Development and Cognition: Section D), 12, 453-467.

Randhawa, B. K., Farley, B. G., \& Boyd, L. A. (2013). Repetitive transcranial magnetic stimulation improves handwriting in Parkinson's disease. Parkinson's Disease, 2013, 751925.

Reis, J., \& Fritsch, B. (2011). Modulation of motor performance and motor learning by transcranial direct current stimulation. Current Opinion in Neurology, 24 $590-596$.

Rektorova, I., Sedlackova, S., Telecka, S., Hlubocky, A., \& Rektor, I. (2007). Repetitive transcranial stimulation for freezing of gait in Parkinson's disease. Movement Disorders, 22, 1518-1519.

Salimpour, Y., Mari, Z. K., \& Shadmehr, R. (2015). Altering effort costs in Parkinson's disease with noninvasive cortical stimulation. Journal of Neuroscience, 35, $12287-12302$.

Serbruyns, L., Leunissen, I., Huysmans, T., Cuypers, K., Meesen, R. L., van Ruitenbeek, P., ... Swinnen, S. P. (2015). Subcortical volumetric changes across the adult lifespan: Subregional thalamic atrophy accounts for age-related sensorimotor performance declines. Cortex, 65, 128-138.

Snijders, A. H., Takakusaki, K., Debu, B., Lozano, A. M., Krishna, V., Fasano, A., ... Hallett, M. (2016). Physiology of freezing of gait. Annals of Neurology, 80, 644-659.

Tahtis, V., \& Kaski, D. (2017). Parkinson's disease treatments: Focus on transcranial direct current stimulation (tDCS). Journal of Parkinsonism and Restless Legs Syndrome, 7, 55-70.

Tanaka, T., Takano, Y., Tanaka, S., Hironaka, N., Kobayashi, K., Hanakawa, T., ... Honda, M. (2013). Transcranial direct-current stimulation increases extracellular dopamine levels in the rat striatum. Frontiers in Systems Neuroscience, 7, 6.

Tard, C., Devanne, H., Defebvre, L., \& Delval, A. (2016). Single session intermittent theta-burst stimulation on the left premotor cortex does not alleviate freezing of gait in Parkinson's disease. Neuroscience Letters, 628, 1-9.

Valentino, F., Cosentino, G., Brighina, F., Pozzi, N. G., Sandrini, G., Fierro, B., ... Pacchetti, C. (2014). Transcranial direct current stimulation for treatment of freezing of gait: A cross-over study. Movement Disorders, 29, 1064-1069.

Van Gemmert, A. W., Adler, C. H., \& Stelmach, G. E. (2003). Parkinson's disease patients undershoot target size in handwriting and similar tasks. Journal of Neurology, Neurosurgery, and Psychiatry, 74, 1502-1508.

Van Gemmert, A. W., Teulings, H. L., Contreras-vidal, J. L., \& Stelmach, G. E. (1999). Parkinson's disease and the control of size and speed in handwriting. Neuropsychologia, 37, 682-694.

Vercruysse, S., Devos, H., Munks, L., Spildooren, J., Vandenbossche, J., Vandenberghe, W., ... Heremans, E. (2012). Explaining freezing of gait in Parkinson's disease: Motor and cognitive determinants. Movement Disorders, 27, 1644-1651.

Vercruysse, S., Gilat, M., Shine, J. M., Heremans, E., Lewis, S., \& Nieuwboer, A. (2014). Freezing beyond gait in Parkinson's disease: A review of current neurobehavioral evidence. Neuroscience \& Biobehavioral Reviews, 43, 213-227.

Vercruysse, S., Spildooren, J., Heremans, E., Vandenbossche, J., Levin, O., Wenderoth, N., ... Nieuwboer, A. (2012). Freezing in Parkinson's disease: A spatiotemporal motor disorder beyond gait. Movement Disorders, 27, 254-263.

Vercruysse, S., Spildooren, J., Heremans, E., Wenderoth, N., Swinnen, S. P., Vandenberghe, W., \& Nieuwboer, A. (2014). The neural correlates of upper limb motor blocks in Parkinson's disease and their relation to freezing of gait. Cerebral Cortex, 24, 3154-3166.

Whitton, P. S. (1997). Glutamatergic control over brain dopamine release in vivo and in vitro. Neuroscience \& Biobehavioral Reviews, 21 , $481-488$.

Williams, A. J., Peterson, D. S., Ionno, M., Pickett, K. A., \& Earhart, G. M. (2013). Upper extremity freezing and dyscoordination in Parkinson's disease: Effects of amplitude and cadence manipulations. Parkinson's Disease, 2013, 595378.

Ziemann, U., \& Siebner, H. R. (2015). Inter-subject and Inter-session variability of plasticity induction by non-invasive brain stimulation: Boon or bane? Brain Stimulation, 8, 662-663.

Ziv, I., Avraham, M., Dabby, R., Zoldan, J., Djaldetti, R., \& Melamed, E. (1999). Earlv-occurrence of manual motor Parkinson's disease: A quantitative assessment. Acta Neurologica Scandinavica, 99, 106-111. 